of IncA/ $\mathrm{C}_{2}$ plasmid may contribute to the diffusion and maintenance of $b l a_{\mathrm{IMP}-1}$ in different groups of bacteria. Considering the concerning spread of carbapenem resistance mediated by plasmids and considering the high prevalence of ST648 E. coli, our study highlights the importance of continuous surveillance studies of carbapenemase genes in Latin America.

Acknowledgments. The authors would like to thank Helena de Ávila Peixoto e Silva for technical support.

Financial support. This work was supported by Instituto Nacional de Pesquisa em Resistência Antimicrobiana Brazil (INCT/CNPq grant no. 465718/2014-0 and INCT/FAPERGS grant no: 17/2551-0000514-7) and by Fundo de Incentivo à Pesquisa e Eventos do Hospital de Clínicas de Porto Alegre (FIPE/HCPA grant no. 2018-0205). P.L.W. and D.L.M. were supported by a grant from the Coordenação de Aperfeiçoamento de Pessoal de Nível Superior (CAPES). E.K.A. was supported by a grant from Conselho Nacional de Desenvolvimento Científico e Tecnológico (CNPq). M.N.C. was supported by a grant from Fundação de Amparo à Pesquisa do Rio Grande do Sul (FAPERGS). A.L.B. and A.P.Z. are a research fellow of the CNPq.

Conflicts of interest. All authors report no conflicts of interest relevant to this article.

\section{References}

1. Watanabe M, Iyobe S, Inoue M, Mitsuhashi S. Transferable imipenem resistance in Pseudomonas aeruginosa. Antimicrob Agent Chemother 1991;35:147-51.
2. Zhao WH, Hu ZQ. IMP-type metallo- $\beta$-lactamases in gram-negative bacilli: distribution, phylogeny, and association with integrons. Crit Rev Microbiol 2011;37:214-226.

3. Monteiro J, Widen RH, Pignatari AC, Kubasek C, Silbert S. Rapid detection of carbapenemase genes by multiplex real-time PCR. J Antimicrob Chemother 2012;67:906-909.

4. Harmer CJ, Hall RM. The A to Z of A/C plasmids. Plasmid 2015;80:63-82.

5. Ewers C, Bethe A, Stamm I, et al. CTX-M-15-D-ST648 Escherichia coli from companion animals and horses: another pandemic clone combining multiresistance and extraintestinal virulence? J Antimicrob Chemother 2014;69:1224-1230.

6. Peirano G, van der Bij AK, Gregson D, Pitout JD. Molecular epidemiology over an 11-year period (2000 to 2010) of extended spectrum $\beta$-lactamaseproducing Escherichia coli causing bacteremia in a centralized Canadian region. J Clin Microbiol 2012;50:294-299.

7. Zong Z, Yu R. Escherichia coli carrying the blaCTX-M-15 gene of ST648. J Med Microbiol 2010;59:1536-1537.

8. Johnson JR, Johnston BD, Gordon DM. Rapid and specific detection of the Escherichia coli sequence type 648 complex within phylogroup F. J Clin Microbiol 2017;55:1116-1121.

9. Kim YA, Qureshi ZA, Adams-Haduch JM, Park YS, Shutt KA, Doi Y. Features of infections due to Klebsiella pneumoniae carbapenemase producing Escherichia coli: emergence of sequence type 131. Clin Infect Dis 2012;55:224-231.

10. Mushtaq S, Irfan S, Sarma JB, et al. Phylogenetic diversity of Escherichia coli strains producing NDM-type carbapenemases. J Antimicrob Chemother 2011;66:2002-2005.

\title{
The Legionella contamination of tap water in a brand-new hospital in Japan before patients move in
}

\author{
Itaru Nakamura $\mathrm{PhD}^{1}$, Yuri Miura $\mathrm{PhD}^{2}$, Ayaka Umeda², Rumiko Imura², Yuki Watanabe ${ }^{2}$ and Hidehiro Watanabe $\mathrm{PhD}^{1}$ \\ ${ }^{1}$ Department of Infection Prevention and Control, Tokyo Medical University Hospital, Tokyo, Japan and ${ }^{2}$ Department of Clinical Microbiology, Tokyo Medical \\ University Hospital, Tokyo, Japan
}

To the Editor-Healthcare facilities are potential settings for Legionella infections, and $2 \%-20 \%$ of Legionnaires' disease cases have been estimated to have been acquired at hospitals, long-term care facilities, and clinics. ${ }^{1,2}$ The widespread contamination of Legionella spp in the water systems of healthcare facilities has recently been recognized. ${ }^{3,4}$ The persistent environmental contamination of Legionella spp in water systems can often be difficult to eradicate once the organism colonizes because the organism is likely to continue to survive in dead branches of complex plumbing systems. Furthermore, identifying the sources of Legionella spp contamination in hospital water systems and determining when colonization occurred can be difficult. Because most studies are performed in operational hospitals, the identified relationships

Author for correspondence: Itaru Nakamura, MD, PhD, Department of Infection Prevention and Control, Tokyo Medical University Hospital, 6-7-1 Nishishinjuku, Shinjuku-ku, Tokyo 160-0023, Japan. E-mail: task300@tokyo-med.ac.jp

Cite this article: Nakamura I, et al. (2020). The Legionella contamination of tap water in a brand-new hospital in Japan before patients move in. Infection Control \& Hospital Epidemiology, 41: 998-999, https://doi.org/10.1017/ice.2020.79 between hospital water systems and Legionella are often attributed to old, scaled water pipes.

We evaluated the environmental contamination of Legionella spp before patients moved into a brand-new hospital, which was built by a leading Japanese construction company. The study was conducted in June 2019 at Tokyo Medical University Hospital, a 19-story building that has 905 beds and a 3-story basement (completed in March 2019). Overall, 61 sampling points were selected, including 27 manual faucets, 18 touch-free faucets, and 16 showers in inpatient hospital wards. A hot water sample and a cool water sample were obtained at each sampling point. In total, $122500-\mathrm{mL}$ samples were obtained, starting as soon as the water began to flow, and samples were stored in sterilized bottles. All samples were concentrated on a filtration, followed by treatment at $50^{\circ} \mathrm{C}$ for 30 minutes. These samples were cultured using Wadowsky-Yee-Okuda- $\alpha$-ketoglutarate agar culture medium (Eiken Chemical, Tokyo, Japan). Cultures were incubated in a humid environment for 5 days at $36 \pm 11^{\circ} \mathrm{C}$.

Among the 122 samples taken, 1 sample, from the highest floor, was positive for Legionella spp. Matrix-assisted laser desorption/ 
ionization-time-of-flight mass spectrometry was used to identify the specimen, resulting in a score of 1.77 for L. felleii. No reaction during the serological aggregation test (Denka Seiken, Tokyo) was observed against L. pneumophila serogroup (SG) 1-SG6, L. bozemanii, L. dumoffii, Legionella gormanii, or L. micdadei.

This study is the first report to describe the Legionella contamination of water taps in a brand-new building, before the start of standard usage. Water taps, showers, sinks, and water systems in healthcare facilities have been recognized to be the causes of healthcare-associated legionellosis. ${ }^{3-5}$ Previous studies have not considered the possibility that even brand-new hospital water systems may be at risk for Legionella spp colonization during the building process, which can persist and spread once the hospital is operational. Although Legionella spp contamination in water systems has been associated with water scale, stagnant water, and sediment, brand-new buildings, even prior to active use, may possess contamination risk factors, such as stagnant dead spaces. ${ }^{3}$ This study indicates that we must pay attention to the risks of healthcare-associated waterborne infections, even in brand-new buildings and before patients move in.
Acknowledgements. We thank Lisa Giles, PhD, from Cambridge Proofreading (https://proofreading.org/) for editing a draft of this manuscript.

Financial support. No financial support was provided relevant to this article.

Conflicts of interest. The author declares no conflicts of interest.

\section{References}

1. Soda EA, Barskey AE, Shah PP, et al. Vital signs: healthcare-associated Legionnaires' disease surveillance data from 20 states and a large metropolitan area-United States, 2015. Am J Transplant 2017;17:2215-2220.

2. Amemura-Maekawa J, Kura F, Chida K, et al. Legionella pneumophila and other Legionella species isolated from legionellosis patients in Japan between 2008 and 2016. Appl Environ Microbiol 2018;84:e00721-18.

3. Decker BK, Palmore TN. The role of water in healthcare-associated infections. Curr Opin Infect Dis 2013;26:345-351.

4. Kanamori H, Weber DJ, Rutala WA. Healthcare outbreaks associated with a water reservoir and infection prevention strategies. Clin Infect Dis 2016;62:1423-1435.

5. Laganà $\mathrm{P}$, Caruso G, Piccione $\mathrm{D}$, et al. Legionella spp, amoebae and notfermenting gram-negative bacteria in an Italian university hospital water system. Ann Agric Environ Med 2014;21:489-493.

\section{Reply to "Comparative evaluation of the microbicidal activity of low-temperature sterilization technologies to steam sterilization"}

Randal Eveland PhD, MS (1)

Steris, Mentor, Ohio

To the Editor-This letter is in response to the article by Rutala et $\mathrm{al}^{1}$ that compared the microbial kill of steam, ethylene oxide (ETO), hydrogen peroxide gas plasma (HPGP), and vaporized hydrogen peroxide (VHP) in the presence of salt and serum in standard sterilization cycles.

Unfortunately, at this time, there are no 'standard' gaseous hydrogen peroxide sterilization processes. The article fails to consider that although both HPGP and VHP processes use gaseous hydrogen peroxide as the sterilant, the processes are distinct and different in the way they operate. Even though 28-minute HPGP and VHP cycles are used, these cycles use significantly different concentrations of sterilant. The HPGP exposure is $25.6 \mathrm{mg} / \mathrm{L}$ $\mathrm{H}_{2} \mathrm{O}_{2}$ for 7 minutes whereas the VHP exposure is $9.1 \mathrm{mg} / \mathrm{L} \mathrm{H}_{2} \mathrm{O}_{2}$ for 12 minutes. The importance of disinfectant concentration is explained in the 2008 CDC Guideline for Disinfection and Sterilization in Healthcare Facilities where it is stated that "The more concentrated the disinfectant, the greater is its efficacy and the shorter the time necessary to achieve microbial kill." ${ }^{2}$ For these evaluations with no chamber load, sterilant concentration should have been considered.

The delineation of the gaseous hydrogen peroxide processes like HPGP and VHP, with the subsequent comparisons of efficacy

Author for correspondence: Randal Eveland, E-mail: randal_eveland@steris.com

Cite this article: Eveland R. (2020). Reply to "Comparative evaluation of the microbicidal activity of low-temperature sterilization technologies to steam sterilization". Infection Control \& Hospital Epidemiology, 41: 999-1000, https://doi.org/10.1017/ ice. 2020.122 minus any consideration of sterilant concentration, seems to imply that there is a benefit from plasma within the sterilization process. This contention contradicts the current understanding of the purpose of a gas plasma in HPGP systems, in which it is known that the plasma step has little to no contribution to sterilizer efficacy. In the only research ever published to evaluate the impact of plasma in a HPGP process, the plasma phase appeared to be nonsporicidal. ${ }^{3}$

The detoxifying (residual sterilant removing) effect of the plasma would have no impact on gaseous hydrogen peroxide microbial lethality; thus, the $\sim 3$-fold sterilant concentration difference (25.6 vs $9.1 \mathrm{mg} / \mathrm{L} \mathrm{H}_{2} \mathrm{O}_{2}$ for the HPGP and VHP systems, respectively) is clearly responsible for the observed efficacy differences in HPGP and VHP processes. Higher concentration is not always beneficial. Beyond efficacy, hospitals also consider the gentleness of the sterilization process to include the potential impact of higher sterilant concentrations and higher sterilant dose on device material compatibility (especially devices susceptible to reaction with the highly oxidizing hydrogen peroxide sterilant) or device biocompatibility as well as the potential impact of plasma on medical device surfaces.

Both the HPGP and VHP sterilization cycles have been cleared by the Food and Drug Administration (FDA), so both have demonstrated the ability to achieve a sterility assurance level (SAL) of 10E-6 for their claimed processes. The CDC disinfection guidelines ${ }^{2}$ specify that even salts dissolved within surrogate body fluids dissolve with 60 seconds of nonflowing water; therefore, showing 